\title{
Current aspects and future trends of computer-aided rescaffolding
}

\author{
Karl-Heinz Baringhaus*, Gerhard Hessler, Thomas Klabunde \\ From 5th German Conference on Cheminformatics: 23. CIC-Workshop \\ Goslar, Germany. 8-10 November 2009
}

The competitive pressure in pharmaceutical industry is reflected by longer development times and increasing development costs yielding less new chemical entities. In particular, identification of suitable lead compounds is one of the key challenges in early drug discovery. Next to well established techniques like high throughput screening (HTS) and virtual screening computer-aided rescaffolding has become an important approach in detecting novel chemical structures $[1,2]$.

The development of New Chemical Entities (NCEs) requires the exploration of novel landscapes in chemical space. Rescaffolding is in particular important in lead identification but also in lead optimization. If a lead series cannot be optimized in multidimensional space, scaffold-rescuing is often perceived as back-up strategy to transfer hitherto available SAR into a new scaffold.

With a binding site or a pharmacophore in hand often de novo design methods are applied to identify novel chemical matter. However, de novo design differs from rescaffolding in that the goal of the first is primarily to generate new molecules in chemical space while the latter aims to design new scaffolds under constraints: high similarity in the desired property space and novelty in scaffold space. This allows jumping out of the known region of chemical space towards new regions of chemistry resulting in molecules with similar properties and activities but with novel frameworks.

This talk will focus on ligand-based rescaffolding by taking into account only the topology of reference molecules. Several descriptors have been successfully applied for rescaffolding purposes, e.g. CATS (including CATS3D), Feature Trees (cf. ReCore), Topomers, Gaussian shape (cf. ROCS, BROOD) and others. In fragmentbased rescaffolding new molecules are assembled from small (sub-) molecular fragments or building blocks

Sanofi-Aventis Deutschland GmbH, CAS Drug Design, Building G 878, 65926 Frankfurt am Main, Germany often by applying pseudo-chemical rules in their recombination (e.g., RECAP). The use of fragments reduces the sampling rate of chemical space and provides access to synthesizable new compounds. This will be exemplified by two rescaffolding examples taking into account $2 \mathrm{D}$ as well as $3 \mathrm{D}$ descriptors.

\section{Published: 4 May 2010}

\section{References}

1. Krueger BA, Dietrich A, Baringhaus K-H, Schneider G: Scaffold-Hopping Potential of Fragment-Based De Novo Design: The Chances and Limits of Variation. Combinatorial Chemistry \& High Throughput Screening 2009, 12(4):383-396.

2. Mauser H, Guba W: Recent developments in de novo design and scaffold hopping. Current Opinion in Drug Discovery \& Development 2008, 11(3):365-374.

\section{doi:10.1186/1758-2946-2-S1-019}

Cite this article as: Baringhaus et al:: Current aspects and future trends of computer-aided rescaffolding. Journal of Cheminformatics 2010 2(Suppl 1):019.

\section{Publish with ChemistryCentral and every scientist can read your work free of charge \\ "Open access provides opportunities to our colleagues in other parts of the globe, by allowing anyone to view the content free of charge." W. Jeffery Hurst, The Hershey Company. \\ - available free of charge to the entire scientific community \\ - peer reviewed and published immediately upon acceptance \\ - cited in PubMed and archived on PubMed Central \\ - yours - you keep the copyright \\ Submit your manuscript here: \\ http://www.chemistrycentral.com/manuscript/

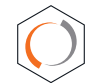 Chemistry Central}

